\title{
The impact of atmospheric blocking on the compounding effect of ozone pollution and temperature: A copula-based approach
}

\author{
Noelia Otero $^{1,2,3}$, Oscar Jurado ${ }^{2}$, Tim Butler ${ }^{1,2}$, and Henning W. Rust ${ }^{2}$ \\ ${ }^{1}$ Institute for Advanced Sustainability Studies, Potsdam, Germany \\ ${ }^{2}$ Institut für Meteorologie, Freie Universität Berlin, Germany \\ ${ }^{3}$ Now at Oeschger Centre for Climate Change Research (OCCR), Bern, Switzerland
}

Correspondence: Noelia Otero (noelia.otero@giub.unibe.ch)

\begin{abstract}
Ozone pollution and high temperatures have adverse health impacts that can be amplified by the combined effects of ozone and temperature. Moreover, changes in weather patterns are expected to alter ozone pollution episodes and temperature extremes. In particular, atmospheric blocking is a high-impact large-scale phenomenon at mid-high latitudes that has been associated with temperature extremes. This study examines the impact of atmospheric blocking on the ozone and temperature dependence among measurement stations over Europe. We use a copula-based method to model the dependence between both variables under blocking and non blocking conditions. This approach allows to examine the impact of blocks on the joint probability distribution. Our results showed that blocks lead to an increasing strength in the upper tail dependence of ozone and temperature extremes ( $>95$ th) in north-west and central Europe (e.g UK, Benelux, north-west of France and Germany). The analysis of the probability hazard scenarios revealed that blocks generally enhance the probability of compound ozone and temperature events by $20 \%$ in a large number of stations over central Europe. The probability of ozone or temperature exceedances increases $30 \%$ (on average) under the presence of atmospheric blocking. Furthermore, we found that in a number of stations over north-western Europe atmospheric blocking increases the probability of ozone exceedances by $30 \%$ given high temperatures. Our results point out the strong influence of atmospheric blocking on the compounding effect of ozone and temperature events, suggesting that blocks might be considered as a relevant predicting factor when assessing the risks of ozone-heat related health effects.
\end{abstract}

\section{Introduction}

Air pollution and heat waves pose a serious risk to health globally (Analitis et al., 2014; WHO, 2015) and evidence suggests that when extreme weather and air pollution episodes occur in coincidence, their health effects are nonlinearly amplified beyond the sum of their individual effects (Willers et al., 2016). Climate change is expected to increase the probability of heat extremes (Seneviratne et al., 2014) and alter air quality (Doherty et al., 2018). Tropospheric ozone is recognised as a harmful pollutant with negative impacts not only to human health, but also to ecosystems (EEA, 2019). Tropospheric ozone is a secondary pollutant formed from complex photochemical reactions of nitrogen oxides $\left(\mathrm{NO}_{\mathrm{x}}\right)$, carbon monoxide $(\mathrm{CO})$ and volatile organic compounds (VOCs) (Seinfeld and Pandis, 2006). The combination of emissions of ozone precursors and specific weather conditions, such as high temperatures, low wind and persistent slow-moving high-pressure systems, favour 
high ozone pollution episodes (Jacob et al., 1993). Temperature has been identified as one of the main meteorological drivers of high ozone episodes in polluted regions over the US (Porter et al., 2015) and most of central Europe (Otero et al., 2016).

Several studies examined the relationship between ozone and temperature extremes and their joint occurrences over the US (Shen et al., 2016; Phalitnonkiat et al., 2018). Phalitnonkiat et al. (2018) measured the joint extremal dependence of ozone and temperature using the spectral dependence of their extremes. They found that temperature and ozone were overall well correlated across many areas over the US, but they noted a reduced correlation when examining the tail of the distribution. Schnell and Prather (2017) examined the co-occurrence of extreme temperatures and air pollution (ozone and fine particulate matter) and they found temperature extremes to be consistently associated in space and time with high levels of ozone over the contiguous US. Sun et al. (2017) estimated a 50\% of conditional probability of high ozone levels given high temperatures in the northeastern US, while less than $20 \%$ was found in the western US. Zhang et al. (2017) compared ozone levels during extreme weather events and non-extreme events and they reported higher ozone levels during extreme weather events, including heat waves, atmospheric stagnation and their compounds. Specifically, they pointed out an enhancement of ozone concentrations when heat waves and atmospheric stagnation events occur simultaneously. Recently, Hertig et al. (2020) analysed combined episodes of heat and ozone pollution waves in two European regions (Germany and Portugal) and their association with mortality rates. This study confirmed the strong impact of compounded heat-ozone waves on excess mortality rates in those regions.

The co-occurrence of extremes are known as a combination of extreme events, which can potentially have a greater impact than the independent hazard event (Zscheischler and Seneviratne, 2017). The compounding effects from high temperature and ozone pollution levels greatly increase the risk to human health (Hertig et al., 2020). Furthermore, the extremes of temperature and high ozone episodes might be exacerbated by underlying climatological drivers (Schnell and Prather, 2017). Large-scale atmospheric circulation is a key driver factor of the variability of surface meteorological variables, including air temperature and extreme temperature events (Pfahl., 2014) and plays an important role in air quality (Russo et al., 2014; Hertig et al., 2020). Extreme weather events are closely linked to anomalies of the atmospheric circulation that can be categorized by "weather regimes" such as cyclones, and atmospheric blocking (Pfahl., 2014). For instance, the extreme temperatures and the lack of precipitation during the summer of 2003 in Europe have been related to the persistent anticyclonic conditions over central

50 Europe (Fink et al., 2004; Solberg et al., 2008). This particular episode led to exceptionally long-lasting and spatially extensive periods of high levels of ozone pollution over Europe (Fiala et al., 2003). Dole et al. (2011) suggested that the persistent blocking of westerly flow was essential during the 2010 heat weave in Russia that killed tens of thousands of people.

Atmospheric blocking is a large-scale phenomenon defined by persistent anticyclones that interrupt the westerly flow in midlatitudes (Barriopedro et al., 2006), and it has been associated with temperature extreme events (Sillmann et al., 2011; Brunner et al., 2017). Pfahl and Wernli. (2012) showed that warm temperature extremes often co-occur with atmospheric blocking at the same location and recently, Röthlisberger and Martius (2019) found that atmospheric blocking also increases the persistence of periods with hot and dry weather conditions that occur concomitantly during summer. A few number of studies have examined the impact of blocks on air pollution. Ordóñez et al. (2017) focused on the regional responses of maximum daily average of $8 \mathrm{~h}$ ozone $\left(\mathrm{MDA}_{3} \mathrm{O}_{3}\right)$ to the persistence of blocks and ridges over Europe. They showed that blocks within the European 
sector (defined as $0-30^{\circ} \mathrm{E}$ ) led to positive anomalies of $\mathrm{MDA} 8 \mathrm{O}_{3}$ over central Europe in spring and summer and found that a considerable proportion of the variability of $\mathrm{MDA} \mathrm{O}_{3}$ exceedances could be explained by blocking patterns. Cai et al. (2020) analysed the influence of persistent blocking conditions on several high pollution episodes of fine particulate matter over northern China. They showed that blocking structures lead to $62.5 \%$ of persistent air pollution events during winter in northern China and pointed out that blocks might be used as an indicative of persistent heavy air pollution in northern China during winter.

The significant linkage between warm extremes and blocking and the strong temperature dependence of ozone motivates the present work that aims to assess the impact of persistent blocks on the compounding effect of ozone and temperature. Here, we measure the dependence structure between ozone and temperature, examining the impact of blocks on the joint distribution. In the context of multivariate processes that may lead to compound events, the application of copula-based probability has been widely used in the recent years (see Hao et al. (2018) and references therein). Copula methods have been extensively applied in hydrological extremes (Salvadori and Michelle, 2010; Hao et al., 2018) and provide a flexible way of construction for a joint distribution with arbitrary marginal distribution (AghaKouchak et al., 2014). Copulas describe the dependence between random variables (Nelsen, 2006) and besides characterizing the overall dependence structure, copulas allow to measure the tail dependence, which is particularly important to assess extreme events (Zscheischler and Seneviratne, 2017; Serinaldi, 2016). In this study, we adopt a copula-based approach to model the joint distribution of temperature and ozone concentrations over Europe during the ozone season (April-September) and quantify the impact of blocks on the joint probability of exceedances.

\section{Data and methods}

Maximum daily average $8 \mathrm{~h}\left(\mathrm{MDA}_{3} \mathrm{O}_{3}\right)$ of ozone concentrations were extracted from the European Environment Agency's air quality database (AirBase) (https://www.eea.europa.eu/data-and-maps/data/) during the period 1999-2015 focusing on the ozone season that spans from April to September. A total of 300 background monitoring stations, including rural, urban and suburban, with altitude $<1000 \mathrm{~m}$ and with at least $75 \%$ of valid data available for each ozone season were used. The number of stations for which measurements are available vary greatly with space, with the major density of stations over central Europe. However, a representative number of stations over northern and southern Europe are also included (Fig. S1).

Daily maximum temperature was derived from the 6-hourly of the $2 \mathrm{~m}$-temperature values extracted from the ERA-Interim (Dee et al., 2011) reanalysis of the European Center for Medium-range Weather Forecasts (ECMWF) for the same period 19992015. The temperature dataset was available at $1^{\circ} \times 1^{\circ}$ regular (latitude/longitude) resolution. Daily $500 \mathrm{hPa}$ geopotential height (Z500) field was obtained from the ERA-Interim reanalysis at a coarser horizontal resolution $2.5^{\circ} \times 2.5^{\circ}$ (latitude/longitude), which is appropriate to characterise large-scale atmospheric circulation.

\subsection{Blocking detection}

90 A 2-dimensional blocking index (BI) derived from daily Z500 was used to identify instantaneously blocked grid points. This blocking index is calculated according to the one-dimensional index proposed by Tibaldi and Molteni (1990) but expanded to 
every latitude and longitude (Scherrer et al., 2006). Similarly as in Barnes et al. (2012), we apply a spatio-temporal filter that allows to exclude small-scale and short-term blocking situations accounting for large-scale and persistent systems between $35^{\circ}$ and $80^{\circ} \mathrm{N}$. Thus, we select contiguously blocked regions with a minimum zonal and meridional extension of $15^{\circ}$ and an area of at least $1.5 \times 10^{-6} \mathrm{~km}^{2}$. A persistent blocking event is considered if the duration of the blocking system lasts a minimum of 4 days. In addition, the tracking algorithm includes possible merging and splittings of the blocking event in time by adopting a blocking overlap area criterion of $7.5 \mathrm{x}^{-6} \mathrm{~km}^{2}$ between two consecutive days and a maximum distance between blocking centers of $1000 \mathrm{~km}$ (Schuster et al., 2019).

The BI was computed through the Free Evaluation System Framework (see Richling et al. (2015) for more details), specifically with the single plug-in corresponding to the blocking-2d (Freva, 2017).

\subsection{Joint distribution analysis}

Recently, copula-based approaches have become very popular to assess interrelations between several random variables (Ribeiro et al., 2019; Salvadori et al., 2016; Hao et al., 2018). A copula is a joint distribution function in which the marginal distributions are independent from the dependence structure and can be modeled separately (Nelsen, 2006). For two random variables random variables $X$ (temperature) and $Y\left(\mathrm{MDA}_{3}\right)$ with marginal distributions $F_{X}(\mathrm{x})=\operatorname{Pr}(X \leq \mathrm{x})$ and $F_{Y}(\mathrm{y})=\operatorname{Pr}(Y \leq \mathrm{y})$ respectively, a copula function allows to construct their joint cumulative distribution as follows:

$F_{X Y}(x, y)=C\left(F_{X}(x), F_{Y}(y)\right)$

where $\mathrm{C}$ is the copula of the transformed random variables $\mathrm{U}=F_{X}(\mathrm{X})$ and $\mathrm{V}=F_{Y}(\mathrm{Y})$, with the marginals $\mathrm{U}$ and $\mathrm{V}$ being uniformly distributed on the interval [0,1]. According to the Sklar's theorem, if the marginal distributions are continuous, then the copula function C is unique (Sklar, 1996). The main advantage of using copula functions is the flexibility to model the dependence between multiple variables with different univariate marginal distributions. For each station we use bivariate copulas to model the dependence between temperature and ozone and estimate their joint probability distribution under two different synoptic situations: 1) with blocking (when $\mathrm{BI}=1$ ), 2) without the presence of blocking (when $\mathrm{BI}=0$ ). We fit a total of four copulas commonly used: t-student (from the Archimedean family), Clayton, Gumbel and Joe (from the elliptical family) (Table 1). The Archimedean copulas are able to describe asymmetric tail behavior, while elliptical copulas capture symetric dependence. Among the different copulas, we selected the structures that are able to capture tail dependence: Gumbel and Joe model upper tail dependence, while Clayton can capture lower tail dependence. The t-student copula allows dependence in both upper and lower tails. Before modelling the join probability distribution we fit the most appropriate marginal distribution

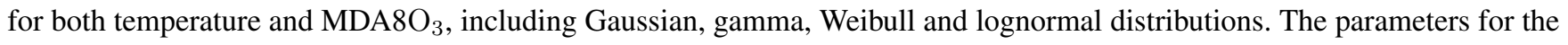
marginal distribution were obtained by the maximum likelihood method. The marginal distributions were selected using the Kolmogorov-Smirnov goodness-of-fit test. For each station and synoptic case $(\mathrm{BI}=1$ and $\mathrm{BI}=0)$ the bivariate copulas were selected based on the Akaike's Information Criteria (AIC) (Akaike, 1974) and the copula parameters were estimated via 
maximum likelihood estimation (MLE). The copula analyses were carried out with the VineCopula and the copula R packages (Schepsmeier et al., 2016; Hofert et al., 2020).

Table 1. Equations of the copula functions

\begin{tabular}{|c|c|c|c|c|}
\hline Copula Family & Function & Parameter range & Upper tail & Lower tail \\
\hline Gumbel & $C(u, v)=\exp \left(-\left[(-\ln u)^{\theta}+(-\ln v)^{\theta}\right)\right]^{\theta}$ & {$[1, \infty)$} & Yes & NO \\
\hline Clayton & $\left.\left.\left.C(u, v)=\left[\max (u)^{(}-\theta\right)+v\right)^{(}-\theta\right) ; 0\right]^{1} / \theta$ & {$[-1, \infty) \operatorname{and}(0,1]$} & No & Yes \\
\hline t-student & $C(u, v)=\int_{-\infty}^{t d f^{-1}(u)} \int_{-\infty}^{t d f^{-1}(v)} \frac{1}{2 \pi \sqrt{1-\rho^{2}}} \exp \left(1+\frac{u^{2}+v^{2}-2 \rho u v}{d f\left(1+\rho^{2}\right)}\right)^{-} \frac{d f+2}{2} d u d v$ & $-1 \leq \rho \leq 1 ; 1 \leq d f$ & Yes & Yes \\
\hline
\end{tabular}
and non blocking $(\mathrm{BI}=0)$ conditions by constructing the corresponding joint probability distribution $(\mathrm{P}(X \leq \mathrm{x}, Y \leq \mathrm{y}))$. Apart from the general dependence structure, some copulas can measure the dependence of the extremes through the tail dependence parameter $\left(\lambda_{u}\right)$ (Nelsen, 2006). As linear or rank dependence measures might not be accurate when focusing on extremes (Hao and Singh, 2016), we have further assessed the upper tail dependence of ozone and temperature extremes derived from the copulas under blocking $(\mathrm{BI}=1)$ and non blocking $(\mathrm{BI}=0)$. We estimate the probability of a compound event at each station, in which Tmax and $\mathrm{MDA}_{8} \mathrm{O}_{3}$ exceed the 95th percentile of their respective distribution. Note that we define compounds of extremes at each station considering the thresholds over the whole distribution (e.g. including non blocked and blocked days) of ozone and temperature. The use of absolute thresholds allows us to quantify the impact of blocks on the probability of exceedances. The probability of exceedances over a certain multivariate threshold was examined based on three different hazard scenarios described by the following joint and conditional joint probabilities, which can be expressed using copula notation (see further details in Serinaldi (2015)):

$P_{A N D}=P(U>u \cap V>v)=1-u-v+C(u, v)$

$P_{O R}=P(U>u \cup V>v)=1-C(u, v)$

$P_{C O N D}=P(U>u \mid V>v)=(1-u-v+C(u, v)) /(1-u)$

The probabilities in equations 2 and 3 have been widely applied in the literature to assess compounds of extremes (Zscheischler and Seneviratne, 2017; Hao et al., 2018). Equation 2 represents the scenario in which both variables temperature (Tmax) and ozone $\left(\mathrm{MDA}_{8} \mathrm{O}_{3}\right)$ exceed the 95th percentile, while equation 3 consider the events occurred when either temperature or ozone or both exceed their respective threshold (95th). As blocks normally lead to persistent positive surface temperature 
anomalies during summer over Europe (Pfahl and Wernli., 2012), it is of interest to evaluate the influence of blocking on the probability of ozone exceedances given high temperatures, which is assessed in the COND scenario.

To quantify the significant impact of blocks on the compound ozone and temperature events, we estimated the differences between the probabilities derived from the copulas (i.e $\Delta P=P_{1}-P_{0}$ ). Then, we assess whether the difference between the probabilities when $\mathrm{BI}=1$ and $\mathrm{BI}=0$ are significantly different from zero. To do so, we apply a bootstrap procedure for each probability scenario (i.e. $A N D, O R, C O N D$ ) in which we drew 100 bootstrapped samples and derived the respective probabilities $P_{1}$ and $P_{0}$ when $\mathrm{BI}=1$ and $\mathrm{BI}=0$, respectively. For the null hypothesis $\left(H_{0}\right)$ there is no difference between the probabilities obtained from the cases $\mathrm{BI}=1$ and $\mathrm{BI}=0$, while the alternative hypothesis indicates that the probability of an extreme event conditioned to a blocking situation is significantly different from the probability under non blocking conditions.

\section{Results}

\subsection{Impact of atmospheric blocking on ozone and temperature}

For the period of study (1999-2015) a total of 3111 days were analysed during the ozone season (April-September). The blocking frequency (\% of days) ranges between $5 \%$ in the southern latitudes $\left(30-45^{\circ} \mathrm{N}\right)$ and $14 \%$ in the northern latitudes $(60-$ $70^{\circ} \mathrm{N}$ ) (Fig. S1). In central Europe, where the density of stations is higher, the frequency of blocked days is $\sim 8 \%$. Typically, blocking presents a well established climatology in terms of frequency in the North Hemisphere, being more frequent in winter and spring, and less frequent in autumn (Barnes et al., 2012; Wollings et al., 2018). During summer, blocking events have shown a tendency to occur at high latitudes over continental areas (Barriopedro et al., 2010). In contrast with previous related studies analysing the seasonal responses of air pollution to blocks (Ordóñez et al., 2017; Garrido-Perez et al., 2017), our study focuses on the whole ozone season during which the compounding effect ozone and temperature is particularly relevant for human health (Hertig et al., 2020). Moreover, atmospheric blocking events are likely to have major impact due to their connection with heatwaves in spring and summer (Brunner et al., 2017). Before presenting the copula modeling results, we begin by examining the individual effect of atmospheric blocking on both variables, $\mathrm{MDA} 8 \mathrm{O}_{3}$ and $\mathrm{Tmax}$ and their relationship under the influence of blocking. We focus first on the impact of blocks on ozone pollution and examine the anomalies of $\mathrm{MDA} 8 \mathrm{O}_{3}$ under blocking conditions. The anomalies were calculated with respect to the corresponding climatology of $\mathrm{MDA} 8 \mathrm{O}_{3}$ during the ozone season (April-September) for the period of study 1999-2015. In general, most of the stations show positive anomalies of $\mathrm{MDA} 8 \mathrm{O}_{3}$ under blocking days, (Fig.1, left). The strongest positive anomalies $>30 \mu \mathrm{gm}^{-3}$ are observed over south of Germany, northeast of France and north-west of Italy, while weaker anomalies are found over Scandinavia, west of the UK and north of Spain. Similarly, Ordóñez et al. (2017) reported strong positive anomalies over large areas of central and north of Europe in spring and summer respectively. Blocks led to positive anomalies of Tmax over all of the stations included in this study (Fig. 2, right). Temperature anomalies display a west-east gradient with the largest values $\left(>7^{\circ} \mathrm{C}\right)$ over the central and western stations (north-east of France, south of Germany and Austria). This is consistent with the radiative heating due to enhanced clear sky conditions over continental areas under atmospheric blocking conditions, especially in summertime (Brunner et al., 2017). 

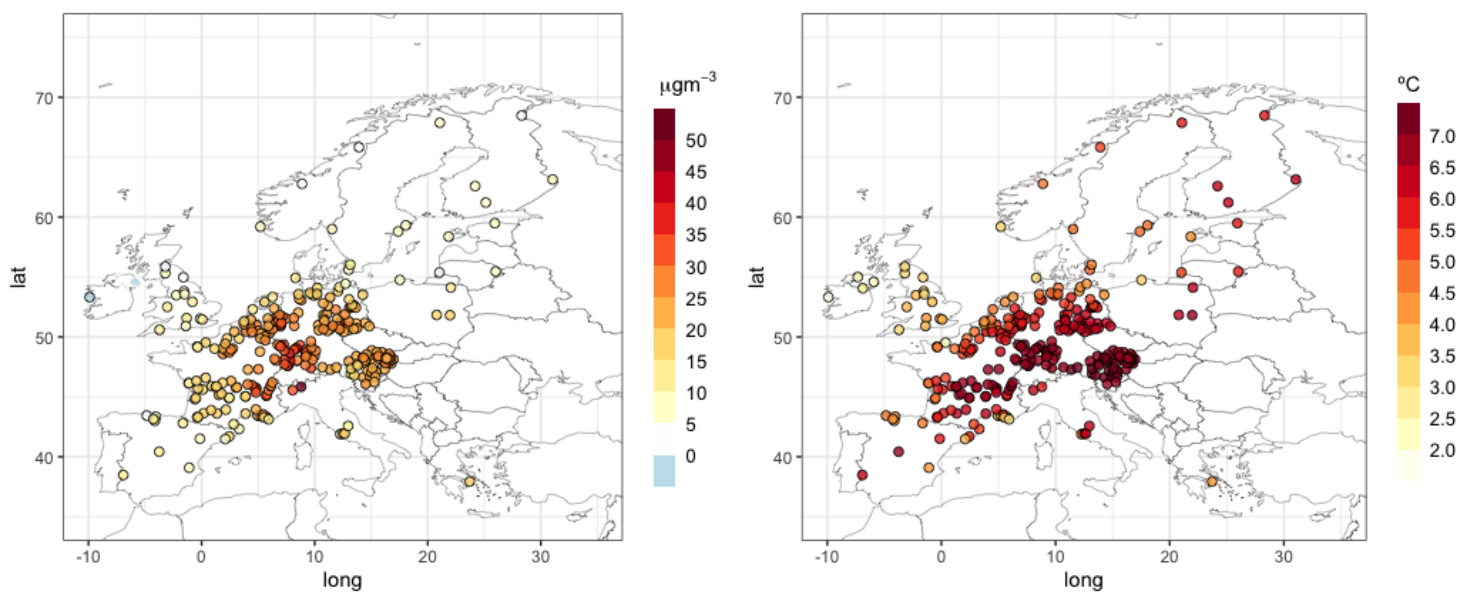

Figure 1. Anomalies of MDA8O3 (left) and Tmax (right) under blocking conditions (days in which $\mathrm{BI}=1$ ) calculated with respect the MDAO3 concentrations over the whole period 1999-2015 during the ozone season, April-September. Black contour indicates statistically significant anomalies at the $95 \%$ confidence level of a two-sided t test.

We further examined the impact of blocking on individual extremes of ozone and temperature defined as the excedancees of the 95th percentile of $\mathrm{MDA} 8 \mathrm{O}_{3}$ and Tmax, respectively. It must be noticed the spatial variability of high levels of ozone (Fig. S2). The 95th percentile of $\mathrm{MDA}_{8} \mathrm{O}_{3}$ exceeds the European target value of $\mathrm{MDA}_{3} \mathrm{O}_{3}\left(120 \mu \mathrm{gm}^{-3}\right.$, EEA (2019)) in a large number of stations in central and south Europe. Only in the case of northern stations (UK, Scandinavia) $\mathrm{MDA} \mathrm{O}_{3}$ would not often exceed the mentioned target value (Fig. S2).

Figure 2 illustrates the frequency of blocked single extremes of ozone and temperature. More than $40 \%$ of $\mathrm{MDA}_{3} \mathrm{O}_{3}$ extremes coincide with blocked days over most of the central stations. The frequency of blocked days of $\mathrm{MDA} 8 \mathrm{O}_{3}$ extremes is generally lower in the southern stations. The percentage of Tmax extremes coincident with blocks increases north and eastwards, witch is consistent with subsidence processes and clear-sky radiative forcing associated with summer blocking events (Pfahl and Wernli., 2012; Sousa et al., 2018).

To investigate the impact of blocks on the relationship between $\mathrm{MDA}_{3} \mathrm{O}_{3}$ and Tmax, the Kendall's tau coefficient $(\tau)$ was calculated during blocking and non blocking days (Fig.3). The correlations are weaker under non-blocking days (BI=0) and a few number of northern stations show negative values. In general, the dependence between $\mathrm{MDA} 8 \mathrm{O}_{3}$ and $\mathrm{Tmax}$ is higher under the influence of blocks. Consistent with previous work, the central stations show the strongest relationship between ozone and temperature (Otero et al., 2016), which significantly increases when $\mathrm{BI}=1$ with the largest correlation values $(>0.6)$. Blocks seem to have a great influence over the north-west of Europe (UK, north of France and Benelux), where the correlations are higher and mostly positive under blocking conditions, while negative correlations are found under non blocking. A similar pattern was found when calculating the correlations for the respective extremes based on the 95th percentile that showed the strongest relationship under the influence of blocks over a large number of stations of France, Germany and UK (Fig. S3). The impact of blocks in the relationship between $\mathrm{MDA} \mathrm{O}_{3}$ and Tmax is smaller in the south and north-east, which is reflected 


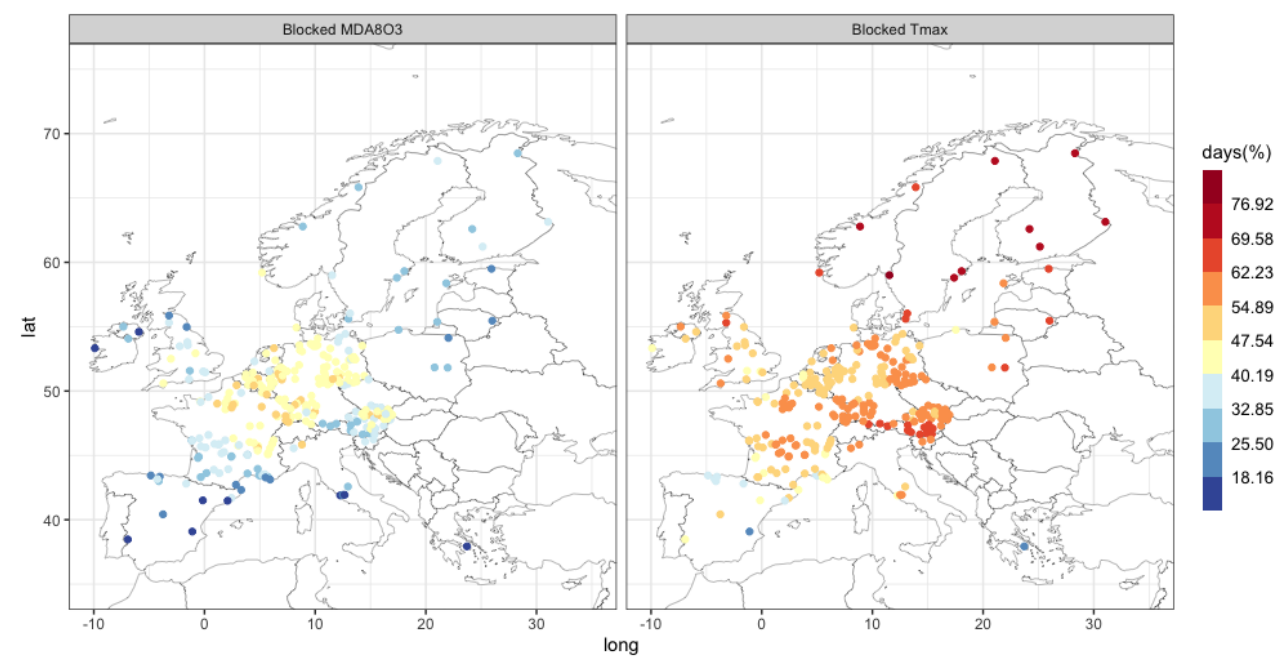

Figure 2. Percentage of days with MDA8O3 (left) and Tmax (right) exceedances ( $>95$ th) that are blocked days.

by not significant and weaker correlations that show similar magnitude values when BI=1 and BI=0. Ordóñez et al. (2017) analysed the impact of subtropical ridges on ozone, and they found a major impact of subtropical ridges in the central-south European sectors. Nevertheless, they pointed out that influence of ridges for the build-up of ozone pollution is not as clear as in the case of blocks and its impact is more sensitive to the location. Blocks play an important role in warm temperature anomalies in spring and summer over central Europe, while the impact is generally lower over south, mostly due to the position of the block (Sousa et al., 2018). Consistent with our results that show a weaker relationship between $\mathrm{MDA} 8 \mathrm{O}_{3}$ and Tmax, we can anticipate significant spatial differences in the impact of blocks on the compounds of extremes of ozone and temperature and their joint distribution.

\subsection{Copula results}

Among the different types of copulas presented in the literature, a total of four copulas (table 1) were tested to find the most appropriate fit that characterises the relationship between $\mathrm{MDA} 8 \mathrm{O}_{3}$ and $\mathrm{Tmax}$ at each station. Our copula choice was mainly motivated by their ability to represent joint tail dependence (upper and/or lower). After modelling the dependence between both variables when $\mathrm{BI}=1$ and $\mathrm{BI}=0$ separately, we quantify the effect of atmospheric blocking on compound extremes of ozone and temperature through the differences between probabilities derived from the cases mentioned above $(\mathrm{BI}=1$ and $\mathrm{BI}=0)$ for each probability scenario. The impact of blocks on the joint behaviour between $\mathrm{MDA}_{8} \mathrm{O}_{3}$ and Tmax is reflected in the selected copula (Fig S4). When BI=0 a large number of stations are characterized by an asymmetric dependence structure as it is the case of Joe and Gumbel copulas. The Gumbel copula is also selected in a number of stations when BI=1, but in this case the $t$ copula is representative for a major number of stations. On the contrary than the Gumbel and Joe copulas, the $t$ copula belongs to the Elliptical and radially symmetric copulas, but capturing dependence in the extremes in both lower and upper tail 


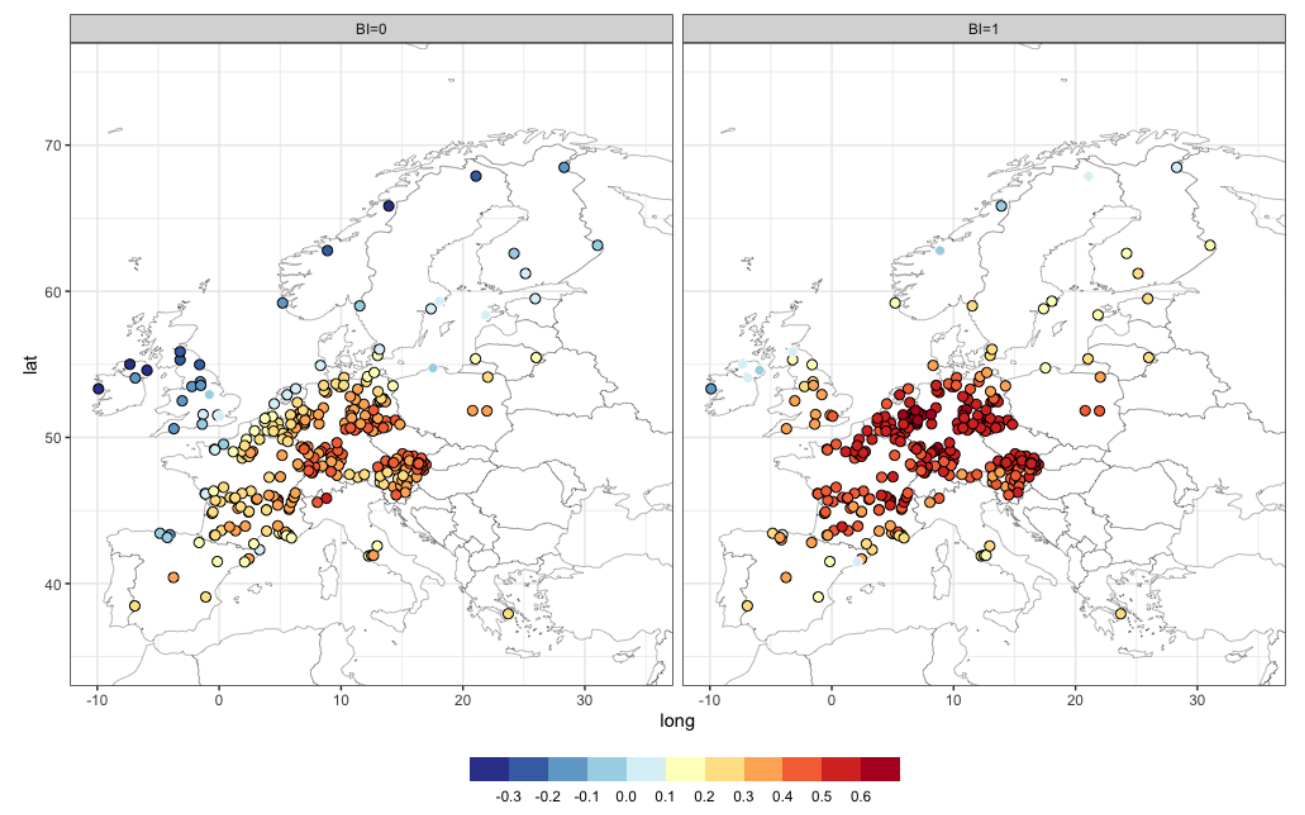

Figure 3. Spatial distribution of the Kendall's correlation coefficient under non blocking contidions (i.e. BI=0, left) and blocking conditions (i.e $\mathrm{BI}=1$, right). Black contour indicates statistically significant anomalies at the $95 \%$ confidence level of a two-sided t test.

(Nelsen, 2006). We further investigated the influence of blocks on the upper tail dependence parameter, $\lambda_{u}$, obtained from the chosen copulas. The $\lambda_{u}$ measures the tendency of concurrent extremes of $\mathrm{MDA} 8 \mathrm{O}_{3}$ and Tmax exceeding the 95th. According to Fig. 4, the strongest upper tail dependence occurs under the influence of blocks over north-west and central Europe (e.g. UK, France, Benelux and north of Germany). The impact of blocks is particularly noticeable over the UK and Benelux with an increase in the dependence of extremes when $\mathrm{BI}=1$. This pattern is in agreement with the relationship obtained by Kendall's $\tau$ (Fig.S3) that shows a stronger relationship of extremes under the influence of blocking conditions.

We use three hazard scenarios $(A N D, O R, C O N D)$ to quantify the impacts of blocks on compounds of extremes of $\mathrm{MDA}_{8} \mathrm{O}_{3}$ and Tmax. The probabilities associated to each type of hazard scenario are defined based on the domain where they are estimated and the critical region related to the probability type (see Fig. S5 for an illustrative example as shown in Serinaldi (2016)). We start analysing the impacts of blocks in the probability of concurrent events of high ozone pollution and hot days using the scenario $A N D$ (Fig. 5, a and b). While there is a very low probability in the co-occurrence of extremes when $\mathrm{BI}=0$ $(<2.5 \%)$, the presence of blocking generally increases the probability of compounds of $\mathrm{MDA} 8 \mathrm{O}_{3}$ and Tmax (Fig. 5 a). Under blocking condtions ( $\mathrm{BI}=1)$, the probability of co-occurrent extremes is $\sim 20 \%$ in most of the stations over central Europe, and $\sim 10 \%$ over the UK (Fig.5 a). The probability of occurrence of compounds of $\mathrm{MDA} 8 \mathrm{O}_{3}$ and $\mathrm{Tmax}$ significantly increases by more than $18 \%$ in a large number of stations over Europe, as shown by the $\Delta P$ (Fig. 5 b). Despite that ozone concentrations and temperature are generally lower over the UK (Fig.S1) compared to other regions, it is interesting to note that blocks seem to play a significant role in the compounding effect ozone and emperature over the UK. Kalisa et al. (2018) analysed the 


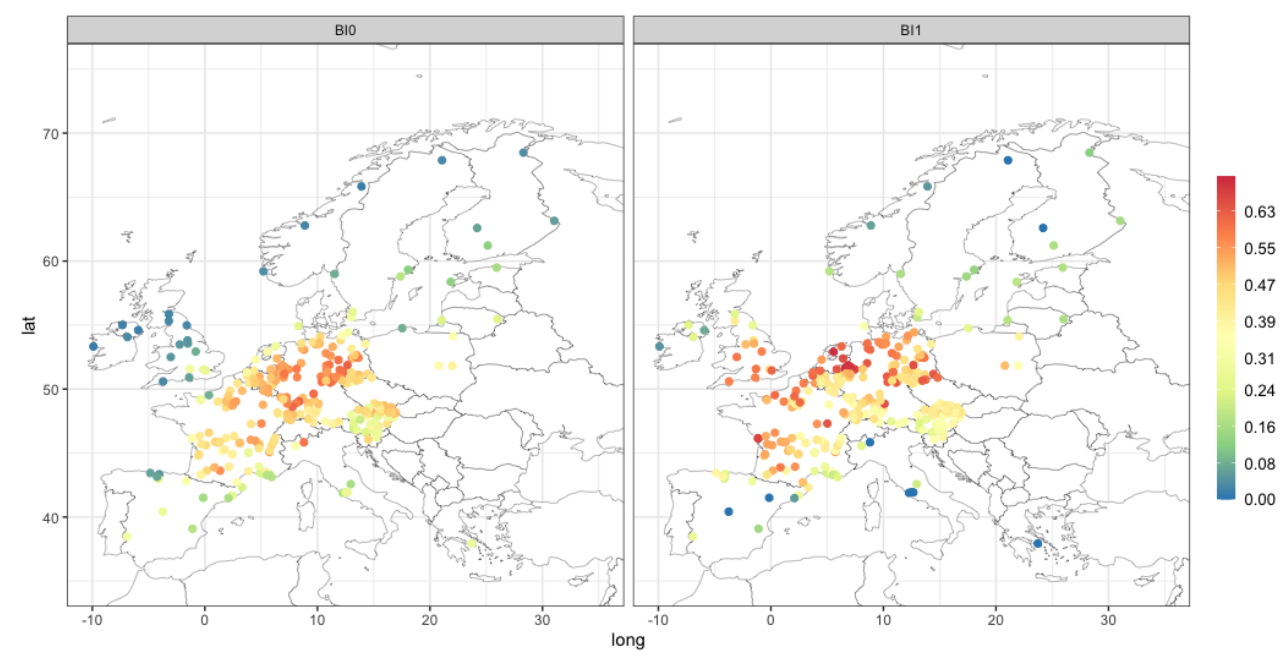

Figure 4. Spatial distribution of the upper tail dependence parameter derived from the copulas when $\mathrm{BI}=0$ (left) and $\mathrm{BI}=1$ (right).

influence of heatwaves on air pollution in the UK, especifically Birmingham and they found that ozone levels increased by more than $50 \%$ with high temperature. Here, we consistently show the combined effect ozone and temperature, and our results also indicate that such combination mainly occurs under blocks likely due to the clear-sky radiative forcing as pointed out by earlier work (Brunner et al., 2017) and subsidence processes associated with the anticyclonic circulation (Pfahl., 2014). The stations over the north-eastern and south-western stations (i.e. Scandinavia and Spain, respectively) exhibit the lowest probability of compounds of extremes of $\mathrm{MDA} \mathrm{O}_{3}$ and Tmax. As shown in Fig. 4 those stations are characterised by low or null upper tail dependence, which already indicates a weak relationship between the extremes. In addition, it is noteworthy the distinct response of heatwaves to blocking found in northern and southern Europe especially in summer (Brunner et al., 2017; Sousa et al., 2018), during which an increasing frequency of heatwaves linked to blocks has been observed over northern Europe, while an opposite response was found in southern Europe (Sousa et al., 2018). Therefore, one could expect a smaller impact of blocks on the compounding effect of ozone pollution and high temperatures in the case of the southern regions. Our results are in agreement with the study carried out by Hertig et al. (2020) that found a lower number of compounds ozone-heat waves events in Portugal compared to the compounds identified in Germany (Bavaria).

We examine the $O R$ scenario under the assumption that blocks might enhance the probability of either high ozone pollution levels or hot temperatures, being both relevant for health impacts (Analitis et al., 2014; Bell et al., 2004). As shown in Fig. 5 (c), the probability obtained for the $O R$ scenario is considerably higher when $\mathrm{BI}=1$, reflecting the strong impact of blocks on single extremes events. Atmospheric blocking conditions enhance the probability that either $\mathrm{MDA} 8 \mathrm{O}_{3}$ or Tmax exceeded the 95th percentile more than $40 \%$ in a large number of stations mostly concentrated in Germany, Austria and east of France. For the rest of the stations, the probability of extremes in the OR scenario increase by 20-30\% under blocking conditions (Fig.5, d). Consistently with previous works that showed the strong association of warm temperature extremes and blocking (Pfahl and Wernli., 2012; Brunner et al., 2017), as well as the impact of blocks on ozone pollution over some European sectors (Ordóñez 
et al., 2017), our results show the increasing probability of temperature $O R$ ozone pollution extremes under atmospheric blocking.

255 From a risk assessment perspective, the scenario $C O N D$ is also of interest, as it quantifies the impacts of blocks of ozone pollution extremes events conditioned on high temperature. For the COND probability, both the computation domain and the critical region evolve when moving along higher temperatures and then, the probability is computed over a reduced subset (e.g. conditioned on temperature extremes) (see Serinaldi (2016) for further details and Fig. S5). As illustrated in Fig. 5 (e and f), blocks generally enhance the probability of extremes of ozone pollution conditioned on temperature exceedances. Blocks significantly influence the compounds in the stations over north-west and central-east of Europe that show positive and large values of $\Delta P$ (Fig. 5, f), suggesting a higher probability of ozone pollution extremes when temperature exceedes the 95th. In particular, blocks lead to an increasing probability of ozone extremes given high temperatures in the UK ( $>40 \%)$. In a few number of stations over south and north-eastern of Europe, blocks did not show a significant influence in the conditional probability of extremes, with low and non significant values of $\Delta P$. For some of these stations the copula selected when $\mathrm{BI}=1$ is the Clayton copula (Fig. S1), which indicates greater probability of joint extreme low values (lower tail dependence), but not in the upper tail as shown in Fig. 5 (e and f). In such cases, the presence of blocks is not relevant for ozone pollution exceedances that seem to occur independently of temperature extremes. 

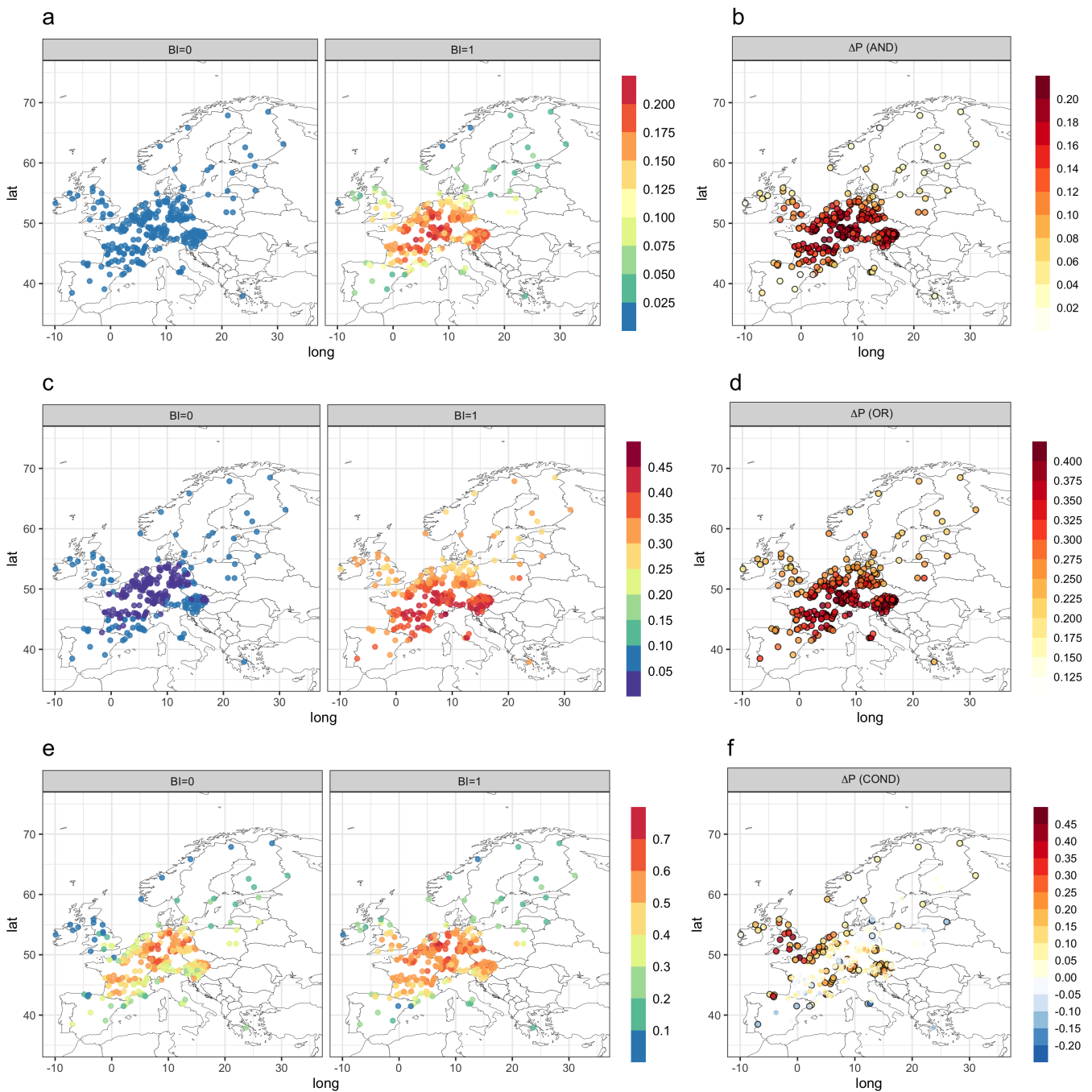

Figure 5. Probability scenarios AND ( $a$ and b), OR (c and d) and COND (e and $\mathrm{f}$ ) derived from the copula analysis when $\mathrm{BI}=1$ and $\mathrm{BI}=0$ (a, c and e). $\Delta \mathrm{P}(\mathrm{b}, \mathrm{d}$ and $\mathrm{f}$ ) shows the difference between the probabilities when $\mathrm{BI}=1$ and $\mathrm{BI}=0$. Black contours represent statistically significance at the confidence level of $95 \%$. 


\section{Discussion and conclusions}

The present study has assessed the influence of atmospheric blocking on the dependence between maximum daily average of $8 \mathrm{~h}$ ozone $\left(\mathrm{MDA}_{8} \mathrm{O}_{3}\right)$ and daily maximum temperature (Tmax) for the period 1999-2015 during the ozone season (AprilSeptember). A total of 300 monitoring stations distributed over Europe were included. First, we examined the blocking influence on single extremes events of ozone pollution and temperature, defined on the basis of the 95th percentile of their distribution. Using a copula-based approach, we evaluated the impacts of blocks on compound ozone pollution and temperature events taking into account their dependence. For each station, the dependence between ozone and temperature was modelled independently under blocking $(\mathrm{BI}=1)$ and non blocking $(\mathrm{BI}=0)$ conditions. The selected copulas described the dependence structure and the joint behaviour of ozone and temperature. We investigated the impacts of blocks on the risks of compound ozone and temperature events under three different hazard scenarios of probability: $A N D, O R$ and $C O N D$, which are commonly used to study multivariate events.

In agreement with previous studies, our results showed that during the ozone season more than $40 \%$ of ozone exceedances ( $>95$ th) are coincident with blocked days over the central stations (including Germany, east of France and Benelux). The rest of the stations showed a lower frequency $(\sim 25 \%)$ of ozone exceedances during blocking conditions. The frequency of temperature extremes is larger than ozone extremes under blocking conditions and on average $55 \%$ of hot days occur under blocking conditions. The highest frequency is observed in the northern Europe (Scandinavia) with more than the $70 \%$ of temperature-blocked extremes, while the lowest frequency is observed in the southern Europe, witch is consistent with the literature (Brunner et al., 2018; Sousa et al., 2018). The analysis of the dependence between ozone and temperature revealed that atmospheric blocking is a key importance in some regions that showed a strong relationship between ozone and temperature under blocking conditions (e.g. central and eastern Europe). In particular, we found a great impact over the stations in the UK and Benelux where the blocks lead to positive and higher correlation values, while a weaker relationship is observed under non blocking conditions. The copula-based approach confirms the dependence between ozone and temperature under the influence of atmospheric blocking. Moreover, the copulas showed that blocks have a major effect on the upper tail dependence in some stations over the UK, north-west and west of France, Benelux and north of Germany, which suggests that compound ozone and temperature extremes are highly associated and influenced by atmospheric blocking.

Overall, we found that blocks enhanced the probability of occurrence of compound ozone and temperature extremes in a large number of stations included in this study. Our results showed that blocking significantly increased by $\sim 15 \%-20 \%$ (i.e. $\Delta P>0.15)$ the probability of co-occurrent ozone and temperature exceedances the stations over central, north-west and east of Europe. In fact, the probability of combined ozone and temperature extremes under non blocking conditions is rather small everywhere $\left(P_{0}<0.025\right)$. Blocks significantly increase the probability that either ozone or temperature (or both) exceed the 95th percentile. The highest probability values are observed over central and eastward stations in which blocking increase the probability of extremes events ozone or temperature more than $35 \%$. The analysis of the join distribution considering the conditional hazard scenario $(C O N D)$ showed a smaller impact of blocks in some stations where the probability of ozone pollution extremes conditioned on high temperature did not show significant differences in terms of magnitude under non 
blocking conditions. However, we found a significant increase in the conditional probability over the north-west stations and a slightly increase over the central-east stations. This suggests that over such regions ozone extremes tend occur given high temperatures which are strongly connected with atmospheric blocking. This is likely due to the position of the block during the ozone season covering spring and summertime when the increased solar radiation lead to warm temperature in the blocked regions (Brunner et al., 2017; Sousa et al., 2018), which can also explain the high levels of ozone pollution in the blocked regions.

Our study showed a clear influence of blocks in local compound ozone and temperature extremes over a large number of stations. Blocks have a significant impact over the central regions, where peaks of ozone pollution usually exceed the European target value of $120 \mathrm{\mu gm}^{-3}$ (set for the protection of human health, EEA (2019)) and warm temperature extremes are strongly connected with atmospheric blocking (Brunner et al., 2017). Ozone levels are normally lower over northwestern Europe (e.g. UK) as well as temperature compared to the rest of the stations (Fig. 2), however our findings showed that blocking lead to an increased strength of the general dependence between ozone and temperature, and particularly in the tail dependence of extremes. This points out that blocks have a significant impact in the compounding effect of ozone and temperature over northwestern Europe, leading to higher health risks.

Our work highlights the relevance of atmospheric blocking on compounding effect of ozone and temperature events in several European regions, which suggests that the frequency of blocking events might be used as a key predicting factor for assessing the health-related risks of the combined effects of ozone pollution and temperature extremes.

Code and data availability. Observational ozone data used in this study are available at the Airbase database of the European Environment

The ERAInterim reanalysis products are available available on the Climate Data Store (CDS) cloud server: https://cds.climate.copernicus.eu. The code applied is available on reasonable request from the corresponding author

Competing interests. The authors declare no competing interests.

Acknowledgements. We acknowledge Andy Richling for providing the Blocking Index data. This publication was financially supported by Geo.X, the Research Network for Geosciences in Berlin and Potsdam (grant no. SO_087_GeoX). This work was hosted by IASS Potsdam, with financial support provided by the Federal Ministry of Education and Research of Germany (BMBF) and the Ministry for Science, Research and Culture of the State of Brandenburg (MWFK). 


\section{References}

AghaKouchak, A., Cheng, L., Mazdiyasni, O., and A.Farahmand: Global warming and changes in risk of concurrent climate extremes: insights from the 2014 California drought., Geophys. Res. Lett., 41(24), 8847-8852, 2014.

Akaike, H.: A new look at the statistical model identification, IEEE T. Automat. Contr., AC-19, 716-723, 1974.

Analitis, A., Michelozzi, P., D’Ippoliti, D., De’Donato, F., Menne, B., Matthies, F., Atkinson, R., Iñiguez, C., Basagaña, X., Schneider, A., Lefranc, A., Paldy, A., Bisanti, L., and Katsouyanni, K.: Effects of heat waves on mortality:effect modification and confounding by air pollutants, Epidemiology, 25(1), 15-22, 2014.

Barnes, E., Slingo, J., and Woollings, T.: A methodology for the comparison of blocking climatologies across indices, models and climate scenarios., Clim Dyn., 38(11-12), 2467-81, 2012.

Barriopedro, D., García-Herrera, R., Lupo, A., and Herández, E. R.: A climatology of northern hemisphere blocking, J Clim, 19, 1042-1063, https://doi.org/10.1175/JCLI3678.1, 2006.

Barriopedro, D., Garcí-Herrera, R., and Trigo, R.: Application of blocking diagnosis methods to General Circulation Models. Part I: A novel detection scheme, Climate Dynamics, 35, 1373-1391, https://doi.org/10.1007/s00382-010-0767-5, 2010.

Bell, M., McDermott, A., Zeger, S., Samet, J., and Dominici, F.: Ozone and short-term mortality in 95 US urban communities, 1987-2000, JAMA, Nov 17, 292(19):2372-8, https://doi.org/10.1001/jama.292.19.2372, 2004.

Brunner, L., Hegerl, G., and Steiner, A.: Connecting atmospheric blocking to European temperature extremes in springs, J Clim., 30(2), 585-94, https://doi.org/10.1175/JCLI-D-16-0518.1, 2017.

Brunner, L., Schaller, N., Anstey, J., Sillmann, J., and Steiner, A.: Dependence of present and future European temperature extremes on the location of atmospheric blocking, Geophysical Research Letters, 45, 6311- 6320, https://doi.org/10.1029/2018GL077837, 2018.

Cai, W., Xu, X., Cheng, X., Wei, F., Qiu, X., and Zhu, W.: Impact of blocking structure in the troposphere on the wintertime persistent heavy air pollution in northern China, Sci Total Environ, 1, 741:140325, https://doi.org/10.1016/j.scitotenv.2020.140325, 2020.

Dee, D., Uppala, S., and Simmons, A.: The ERA-Interim reanalysis: configuration and performance of the data assimilation system, Q J R Meteorol Soc., 137, 553-597, https://doi.org/10.1002/qj.828, 2011.

Doherty, R., Heal, M., and Connor, F.: Climate change impacts on human health over Europe through its effect on air quality, Environ Health, 16, 118, https://doi.org/10.1186/s12940-017-0325-2, 2018.

Dole, R., Hoerling, M., Perlwitz, J., Eischeid, J., Pegion, P., Zhang, T., Quan, X. W., Xu, T., and Murray, D.: Was there a basis for anticipating the 2010 Russian heat wave?, Geophys.Res.Lett., 38, L06 702, https://doi.org/10.1029/2010GL046582, 2011.

EEA, E. E. A.: Air quality in Europe-2019 report, Tech. rep., 2019.

Fiala, J., Cernikovsky, L., de Leeuw, F., and Kurfuerst, P.: Air pollution by ozone in Europe in summer 2003. Overview of exceedances of EC ozone threshold values during the summer season April-August 2003 and comparisons with previous years, EEA Topic Rep, 2003.

Fink, A., Brücher, T., Krüger, A., Leckebush, G., Pinto, J., and Ulbrich, U.: The 2003 European summer heatwaves and drought -synoptic diagnosis and impacts, Weather, pp. 209-216, https://doi.org/10.1256/wea.73.04, 2004.

Freva: Freie Universität Berlin Evaluation, https://freva.met.fu-berlin.de/, 2017.

Garrido-Perez, J., Ordóñez, , and García-Herrera, R.: Strong signatures of high-latitude blocks and subtropical ridges in winter PM10 over Europe, Atmos Environ., 167, 49-60, 2017.

365 Hao, Z. and Singh, V.: Review of dependence modeling in hydrology and water resources, Prog. Phys. Geogr., 40, 549-578, 2016. 
Hao, Z., Singh, V., and Hao, F.: Compound Extremes in Hydroclimatology: A Review, Water, 718, 10, https://doi.org/10.3390/w10060718, 2018.

Hertig, E., Russo, A., and Trigo, R. M.: Heat and ozone pollution waves in Central and South Europe - characteristics, weather types, and association with mortality, Atmosphere, 11, 1271, https://doi.org/10.3390/atmos11121271, 2020.

Hofert, M., Kojadinovic, I., Maechler, M., and Yan, J.: copula: Multivariate Dependence with Copulas, https://CRAN.R-project.org/package= copula, $\mathrm{r}$ package version 1.0-1, 2020.

Jacob, D., Logan, J., Yevich, R., Gardner, G., Spivakovsky, C., Wofsy, S., Munger, J., Sillman, S., Prather, M., Rodgers, M., Westberg, H., and Zimmerman, P.: Simulation of summertime ozone over North America, J. Geophys. Res., 98, 14 797e14 816, 1993.

Kalisa, E., Fadlallah, S., Amani, M., Nahayo, L., and Habiyaremye, G.: Temperature and air pollution relationship during heatwaves in Birmingham, UK, Sustainable Cities and Society, 43, 111-120, https://doi.org/https://doi.org/10.1016/j.scs.2018.08.033, 2018.

Nelsen, R. B.: An Introduction to Copulas, Springer Science and Business Media, 2006.

Ordóñez, C., Barriopedro, D., García-Herrera, R., Sousa, P., and Schnell., J.: Regional responses of surface ozone in Europe to the location of high-latitude blocks and subtropical ridges, Atmos. Chem. Phys., 17, 3111-3131, https://doi.org/10.5194/acp-17-3111-2017, 2017.

Otero, N., Sillmann, J., Schnell, J. L., Rust, H., and Butler., T.: Synoptic and meteorological drivers of extreme ozone concentrations over Europe, Environ. Res. Lett., 11, 024 005, https://doi.org/10.1088/1748-9326/11/2/024005, 2016.

Pfahl., S.: Characterising the relationship between weather extremes in Europe and synoptic circulation features, Natural Hazards and Earth System Sciences, 14(6), 1461-1475, https://doi.org/10.5194/nhess-14-1461-2014, 2014.

Pfahl, S. and Wernli., H.: Quantifying the relevance of atmospheric blocking for co-located temperature extremes in the Northern Hemisphere on (sub-)daily time scales, Geophysical Research Letters, 39, L12 807, https://doi.org/10.1029/2012GL052261, 2012.

Phalitnonkiat, P., Hess, P. G. M., Grigoriu, M. D., Samorodnitsky, G., Sun, W., Beaudry, E., Tilmes, S., Deushi, M., Josse, B., Plummer, D., and Sudo., K.: Extremal dependence between temperature and ozone over the continental US, Atmos. Chem. Phys., 18, 11927-11948, https://doi.org/10.5194/acp-18-11927-2018, 2018.

Porter, W., Heald, C., Cooley, D., and Russel, B.: Investigating the observed sensitivities of air-quality extremes to meteorological drivers via quantile regression, Atmos. Chem. Phys., 15, 10349-10366, https://doi.org/10.5194/acp-15-10349-2015, 2015.

Ribeiro, A., Russo, A., Gouveia, C., and Páscoa, P.: Copula-based agricultural drought risk of rainfed cropping systems, Agricultural Water Management, 223, 105 689, https://doi.org/10.1016/j.agwat.2019.105689, 2019.

Richling, A., Kadow, C., Illing, S., and Kunst, O.: Freie Universitat Berlin evaluation system (Freva) - blocking. Documentation of the Blocking Plugin, https://doi.org/Online at: https://freva.met.fu-berlin.de/about/blocking/, 2015.

Russo, A., Trigo, R., Martins, H., and Mendes, M.: NO2, PM10 and O3 urban concentrations and its association with circulation weather types in Portugal, Atmos. Environ., 89, 768-785, https://doi.org/10.1016/j.atmosenv.2014.02.010, 2014.

Röthlisberger, M. and Martius, O.: Quantifying the local effect of Northern Hemisphere atmospheric blocks on the persistence of summer hot and dry spells., Geophysical Research Letters, 46, 10 101- 10 111, https://doi.org/10.5194/acp-18-2601-2018, 2019.

Salvadori, G. and Michelle, C. D.: Multivariate multiparameter extreme value models and return periods: a copula approach, Geophys. Res. Lett., 46, W10 501, https://doi.org/10.1029/2009WR009040, 2010.

400 Salvadori, G., Durante, F., Michelle, C. D., Bernardi, M., and Petrella, L.: A multivariate copula-based framework for dealing with hazard scenarios and failure probabilities, Water Resour, 52, 3701-3721, 2016.

Schepsmeier, U., Stoeber, J., Brechmann, E. C., Graeler, B., Nagler, T., and Erhardt, T.: VineCopula: Statistical Inference of Vine Copulas, R package version 2.0.5, https://CRAN.R-project.org/package=VineCopula, 2016. 
Scherrer, S., Croci-Maspoli, M., Schwierz, C., and Appenzeller, C.: Two-dimensional indices of atmospheric blocking and their stahttps://doi.org/10.1002/joc.1250, 2006.

Schnell, J. L. and Prather, M. J.: Co-occurrence of extremes in surface ozone, particulate matter, and temperature over eastern North America, P. Natl. Acad. Sci. USA, 114, 2854-2859, https://doi.org/10.1073/pnas.1614453114, 2017.

Schuster, M., Grieger, J., Richling, A., Scharter, T., Illing, S., Kadow, C., Müller, W. A., Pohlmann, H., Pfahl, S., and Ulbrich, U.: Improvement in the decadal prediction skill of the North Atlantic extratropical winter circulation through increased model resolution, Earth Syst. Dynam., 10, 901-917, https://doi.org/10.5194/esd-10-901-2019, 2019.

Seinfeld, J. and Pandis, S.: Atmospheric Chemistry and Physics: From Air Pollution to Climate Change, 2nd Edn., Wiley, 2006.

Seneviratne, S., Donat, M., Mueller, B., and Alexander, L.: No pause in the increase of hot temperature extremes, Nat. Clim. Change, 4 , 161-163, https://doi.org/10.1038/nclimate2145, 2014.

415 Serinaldi, F.: Dismissing return periods!, Stoch. Environ. Res. Risk Assess., 29, 1179-1189, 2015.

Serinaldi, F.: Can we tell more than we can know? The limits of bivariate drought analyses in the United States, Stoch. Environ. Res. Risk Assess., 30, 1691-1704, 2016.

Shen, L., Mickley, L., and Gilleland, E.: Impact of increasing heat waves on U.S. ozone episodes in the 2050s: Results from a multimodel analysis using extreme value theory, Geophys. Res. Lett., 43, 4017-4025, 2016.

Sillmann, J., Croci-Maspoli, M., Kallache, M., and Katz, R.: Extreme cold winter temperatures in Europe under the influence of north atlantic atmospheric blocking, J. Clim., 24(22), 5899-5913, https://doi.org/10.1175/2011JCLI4075.1, 2011.

Sklar, A.: Random variables, distribution functions, and copulas-a personal look backward and forward. Distributions with fixed marginals and related topics, Institute of Mathematical Statistics, Hayward, CA, https://doi.org/10.1214/lnms/1215452606, 1996.

Solberg, S., Hov, Ø., Søvde, A., Isaken, I. S. A., Coddeville, P., Backer, H. D., Forster, C., Orsolini, Y., and Uhse, K.: European surface ozone in the extreme summer 2003, J. Geophys. Res., 113, D07 307, https://doi.org/10.1029/2007JD009098, 2008.

Sousa, P., Barriopedro, J. D., Soares, P., and Santos, J.: European temperature responses to blocking and ridge regional patterns, Clim. Dynam., 50(1-2), 457-77, https://doi.org/10.1007/s00382-017-3620-2, 2018.

Sun, W., Hess, P., and Liu, C.: The impact of meteorological persistence on the distribution and extremes of ozone, Geophys. Res.Lett., 44, 1545-1553, https://doi.org/10.1002/2016GL071731,2016GL071731, 2017.

430 Tibaldi, S. and Molteni, F.: On the operational predictability of blocking, Dyn Meteorol Ocean., 42(3), 343-65, 1990.

WHO, W. H. O.: Reducing global health risks through mitigation of short-lived climate pollutants: scoping report for policymakers, 2015.

Willers, S., Jonker, M. F., klok, L., Keuken, M., Odink, J., van den Elshout, S., Sabel, C. E., Mackenbach, J., and Burdorf, A.: High-resolution exposure modelling of heat and air pollution and the impact on mortality, Environ Int, 89-90, 102-109, https://doi.org/10.1016/j.envint.2016.01.013, 2016.

Wollings, T., Barriopedro, D., Methven, D., Son, S., Martius, O., Harvey, B., Sillmann, J., Lupo, A. R., and Seneviratne, S.: Blocking and its Response to Climate Change, Curr Clim Change Rep, 4, 287-300, https://doi.org/10.1007/s40641-018-0108-z, 2018.

Zhang, H., Wand, Y., Park, T., and Deng, Y.: Quantifying the relationship between extreme air pollution events and extreme weather events, Atmos. Res., 188, 64-79, https://doi.org/10.1016/j.atmosres.2016.11.010, 2017.

Zscheischler, J. and Seneviratne, S.: Dependence of drivers affects risks associated with compound event, Sci. Adv., 3(6), 1-11, https://doi.org/10.1126/sciadv.1700263, 2017. 